\title{
The Prognostic Value of the 8th Edition of the American Joint Committee on Cancer (AJCC) Staging System in HER2- Enriched Subtype Breast Cancer, a Retrospective Analysis
}

\author{
BIN ZHOU ${ }^{1}$, LING XU $^{1}$, JINGMING YE $^{1}$, LING XIN $^{1,2}$, XUENING DUAN $^{1}$ and YINHUA LIU ${ }^{1}$ \\ ${ }^{1}$ Breast Disease Center, Peking University First Hospital, Beijing, P.R. China; \\ ${ }^{2}$ Cardiff China Medical Research Collaborative, Cardiff University School of Medicine, Cardiff, U.K.
}

\begin{abstract}
Background/Aim: The American Joint Committee on Cancer (AJCC) released its 8th edition of tumor staging which is to be implemented in early 2018. The present study aimed to analyze the prognostic value of AJCC 8th edition Cancer Staging System in HER2-enriched breast cancer, on a retrospective cohort. Patients and Methods: This study was a retrospective single-center study of HER2-enriched breast cancer cases diagnosed from January 2008 to December 2014. Clinicopathological features and follow up data including disease-free survival (DFS) and overall survival $(O S)$ were analyzed to explore prognostic factors for disease outcome. We restaged patients based on the 8th edition of the AJCC cancer staging system and analyzed prognostic value of the Anatomic Stage Group and the Prognostic Stage Group. Results: The study enrolled 170 HER2-enriched subtype breast cancer patients with 5-year disease free survival (DFS) of $85.1 \%$ and 5-year overall survival (OS) of 86.8\%. Prognostic stages of 117 cases (68.8\%) changed compared with anatomic stages, with 116 upstaged cases and 1 downstaged case. The Anatomic Stage Groups had a significant prognostic impact on DFS $\left(\chi^{2}=16.752, p<0.001\right)$ and $O S\left(\chi^{2}=25.038, p<0.001\right)$. The Prognostic Staging Groups had a significant prognostic impact on DFS $\left(\chi^{2}=6.577, p=0.037\right)$ and $O S\left(\chi^{2}=21.762, p<0.001\right)$. In the multivariate analysis, both stage groups were independent predictors of OS. Conclusion: Both Anatomic and Prognostic Stage Groups in the 8th edition of the AJCC breast cancer staging system had prognostic value in HER2-enriched subtype breast cancer. The Prognostic Stage system was a breakthrough on the basis of anatomic staging system.
\end{abstract}

Correspondence to: Prof. Yinhua Liu, Breast Disease Center, Peking University First Hospital, Beijing 100034, P.R. China. Tel: +861083575053, e-mail: liuyinhua@medmail.com.cn

Key Words: Breast cancer, HER2-enriched subtype, AJCC cancer staging system, prognostic value.
The American Joint Committee for Cancer (AJCC) cancer staging system is one of the important tools for physicians to help predict disease progression and make therapeutic decisions. The 8th edition of the AJCC Cancer Staging System, which was promulgated in October 2016, added four biologic factors including tumor grade, estrogen and progesterone receptor expression, human epidermal growth factor receptor 2 (HER2) expression and multigene panels to anatomic stage system, forming novel Prognostic Staging Group table, aiming at providing a more precise tool for prognostic classification (1). This new staging will require more validation for its clinical value in different tumor subtypes, clinical settings, ethnic regions and population as well as long term benefits for the patients. In the present study, we have used a retrospective cohort of Chinese patients with a HER2 enriched subtype of breast cancer and conducted analysis using this new staging method. The value of AJCC 8th edition on HER2 subtype is not known. Here, we report the result of a retrospective study of 170 patients with HER2-enriched breast cancer cases treated in Breast Disease Center, Peking University First Hospital from 1st January 2008 to 31 st December 2014. The 8th edition of the AJCC Cancer Staging System was used to restage all enrolled patients and analyzed prognostic value of Anatomic Stage System and the Prognostic Stage System.

\section{Patients and Methods}

This retrospective study comprised HER2-enriched subtype invasive breast cancer patients newly diagnosed and treated Breast Disease Center, Peking University First Hospital from 1st January 2008 to 31st December 2014. Patients were excluded if clinicopathological information or follow-up data were not available or incomplete.

Histopathological determination of biomarkers. The expression of estrogen receptor (ER), progesterone receptor (PR), HER2 were assessed according to the American Society of Oncology/College of American Pathologist guidelines (2, 3). Histopathologic grade was determined by tubule formation, nuclear pleomorphism, and mitotic 


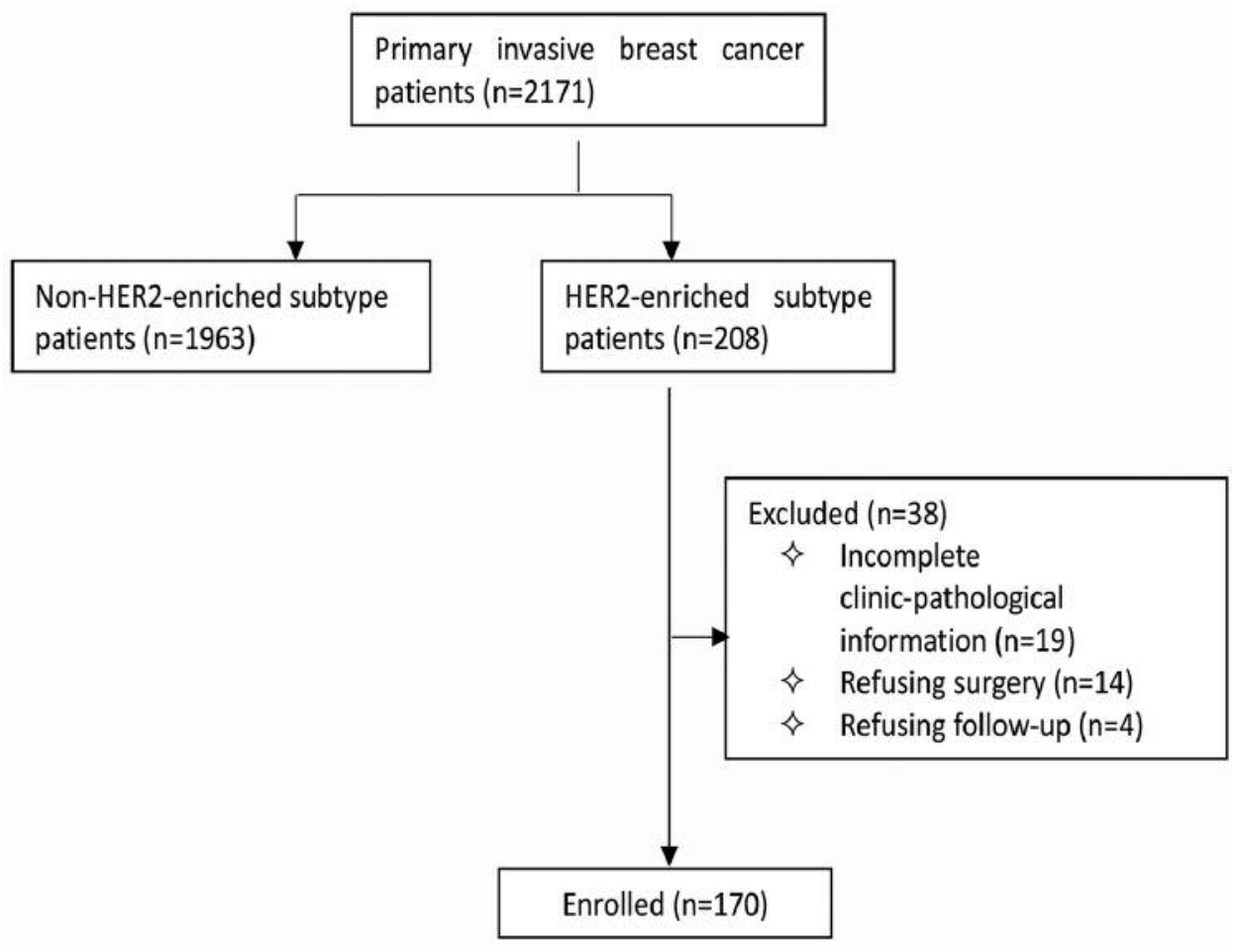

Figure 1. Flow diagram of the study cohort.

count according to Scarff-Bloom-Richardson System-Nottingham Modification (4).

Molecular subtypes. Intrinsic molecular subtypes were determined according to the St. Gallen International Expert Consensus recommendations 2011 (5). HER2-enriched subtype was ER/PR negative and HER2 positive.

Anatomic and prognostic staging. Anatomic and prognostic staging was evaluated according to the 8th edition of the AJCC staging manual (1).

Follow-up. The patients received clinical follow-ups every 12 months. Follow-up data were last updated in December 2016.

Statistical analysis. The data were analyzed using SPSS software version 19.0 (SPSS, IBM Corp, Armonk, NY, USA). Categorical variables were described using rates. Continuous variables were described using medians and interquartile range (IQR). Disease free survival (DFS) was calculated from the day of surgery to the ipsilateral loco-regional relapse or distant metastasis, or censored at the last follow-up. Overall survival (OS) was calculated from the diagnosis to death, or censored at the last follow-up. The relationship between categorical variables was analyzed with Pearson chi-square test. Kaplan-Meier method and log-rank test were used to calculate 5-year DFS and OS, and perform univariate analysis. Factors associated with prognosis in the univariate analysis or wildly acknowledged, were considered in the multivariate analysis using proportional hazard Cox models. Variable selection was backward. $p<0.05$ was considered to be statistically significant.

\section{Results}

Patient demographic information. From 1st January 2008 and 31st December 2014, 2171 primary invasive breast cancer patients were diagnosed in the Breast Disease Center, Peking University First Hospital. A total of 208 cases, 9.6\%) were of the HER2-enriched subtype. One hundred and seventy of the patients were enrolled. The remaining 38 cases were excluded due to incomplete information (Figure 1). All patients were female and the median age was 54 years (IQR=45-62 years). The median follow-up time was 54 months (IQR=31-63 months). The 5-year DFS was $85.1 \%$ and 5-year OS was $86.8 \%$. Patient characteristics are described in Table I.

Results of patients staged by anatomic staging groups. Among all 170 patients, 51 cases $(30.0 \%)$ were anatomic stage I, 74 cases $(43.5 \%)$ were stage II, 34 cases $(20 \%)$ were stage III, 11 cases $(6.5 \%)$ were stage IV (Table II). There were significant differences in DFS $\left(\chi^{2}=16.752, p<0.001\right)$ and $\operatorname{OS}\left(\chi^{2}=25.038, p<0.001\right)$ between anatomic stage groups (Figure 2).

Results of patients staged by prognostic staging groups. Among all 170 patients, 51 cases $(30.0 \%)$ were stage I, 48 cases (28.2\%) were stage II, 60 cases $(35.3 \%)$ were stage III, 11 
cases $(6.5 \%)$ were stage IV (Table II). There were significant differences in DFS $\left(\chi^{2}=6.577, p=0.037\right)$ and OS $\left(\chi^{2}=21.762\right.$, $p<0.001$ ) between prognostic stage groups (Figure 3 ).

Differences between staging results using anatomic and prognostic stage groups. One hundred and seventeen patients $(68.8 \%)$ had different results when staged separately using anatomic and prognostic stage groups among all 170 patients. One hundred and sixteen patients were upstaged in prognostic stage groups compared with anatomic stage groups. Only 1 patient (T3N3M0, grade 1) was downstaged from anatomic stage IIIC to prognostic stage IIIB (Table III). A total of 85 patients $(73.3 \%)$ were grade 3 among the 116 patients who were upstaged. Eleven patients $(26.2 \%)$ were grade 3 out of 42 patients with an unchanged stage. The proportion of patients with grade 3 in the upstaged group was significantly higher than that in the unchanged group $(p<0.001)$.

Results of multivariate analysis. Variables considered in the Cox model included age, anatomic stage, prognostic stage, lymph-vascular invasion, Ki67 $(\leq 30 \%$ or $>30 \%)$. In the multivariate analysis, anatomic stage was the independent predictor of DFS ( $p=0.003)$. Age, anatomic stage, prognostic stage were independent predictors for OS (Table IV).

Anti-HER2 therapy. Trastuzumab therapy was given to 75 cases $(44.1 \%), 95$ cases $(55.9 \%)$ refused anti-HER2 therapy for economic reasons. The proportion of application of trastuzumab was low before 2011 and increased after 2012 (Table V). The proportion of application of trastuzumab was higher in the high-risk subgroup than in the low-risk subgroup, regardless of whether the staging was based on anatomic or prognostic stage groups (Table VI).

Prognostic value of the Prognostic Stage Groups in patients treated with trastuzumab. For patients that had received the anti-HER2 therapy trastuzumab, the 5-year DFS was 92\%, 5 -year OS was $92.6 \%$, better than those patients that did not have anti-HER2 therapy whose 5-year DFS was $80.8 \%$ and 5 -year OS was $83.4 \%$. There were significant differences in OS $\left(\chi^{2}=15.117, p=0.002\right)$ and no significant difference in DFS $\left(\chi^{2}=0.470, p=0.791\right)$ between prognostic stage groups (Figure 4).

\section{Discussion}

Since the 1st edition of the AJCC cancer Staging Manual was published in 1977, the AJCC insisted on seeing anatomic information including primary tumor $(\mathrm{T})$, regional lymph nodes (N) and distant metastases (M) as the fundamental of cancer staging (6). These three anatomic factors formed the TNM staging system, which allow evaluation of tumor burden. The TNM staging system has
Table I. Patient characteristics.

\begin{tabular}{|c|c|}
\hline Characteristic & Number of cases $(\%)$ \\
\hline \multicolumn{2}{|l|}{ Age } \\
\hline$<35$ & $7(4.1)$ \\
\hline $35-65$ & $128(75.3)$ \\
\hline$>65$ & $35(20.6)$ \\
\hline \multicolumn{2}{|l|}{ Menopausal status } \\
\hline Premenopausal & $58(34.1)$ \\
\hline Postmenopausal & $112(65.9)$ \\
\hline \multicolumn{2}{|l|}{ Histological grade } \\
\hline G1 & $4(2.4)$ \\
\hline G2 & $67(39.4)$ \\
\hline G3 & $99(58.2)$ \\
\hline \multicolumn{2}{|l|}{ Histological type } \\
\hline Ductal & $166(97.6)$ \\
\hline Lobular & $1(0.6)$ \\
\hline Others & $3(1.8)$ \\
\hline \multicolumn{2}{|l|}{ Lymphvascular invasion } \\
\hline Yes & $22(12.9)$ \\
\hline No & $148(87.1)$ \\
\hline \multicolumn{2}{|l|}{ Ki-67 status } \\
\hline$\leq 30 \%$ & $60(35.3)$ \\
\hline$>30 \%$ & $110(64.7)$ \\
\hline \multicolumn{2}{|l|}{ Surgical therapy } \\
\hline Breast conserving surgery & $22(12.9)$ \\
\hline Mastectomy & $148(87.1)$ \\
\hline \multicolumn{2}{|l|}{ Axillary staging* } \\
\hline SLNB & $60(35.3)$ \\
\hline ALND & $109(64.1)$ \\
\hline None & $1(0.6)$ \\
\hline \multicolumn{2}{|l|}{ Chemotherapy } \\
\hline Yes & $135(79.4)$ \\
\hline No & $35(20.6)$ \\
\hline \multicolumn{2}{|l|}{ Trastuzumab therapy } \\
\hline Yes & $75(44.1)$ \\
\hline No & $95(55.9)$ \\
\hline
\end{tabular}

*SLNB: Sentinel lymph node biopsy; ALND: axillary lymph node dissection.

become the most widely used and authoritative cancer staging system in the world after several revisions and tested for decades in clinical practice. Compared to anatomic information, pathological characteristics reflect more intrinsic nature as breast cancer is highly heterogeneous (7). In recent years, physicians increasingly pay more attention to the impact of biological factors on prognosis prediction and therapeutic decision making, promoting the evolution from population-based to classification-based treatment. The 8th edition of the AJCC cancer staging system which will be implemented in 1 January 2018, has reflected this aspect, by adding histologic grade (G), ER, PR and HER2 to the TNM staging system for the first time. The newly established staging system was called the Prognostic Staging Groups. Compared with the TNM staging system, called the 

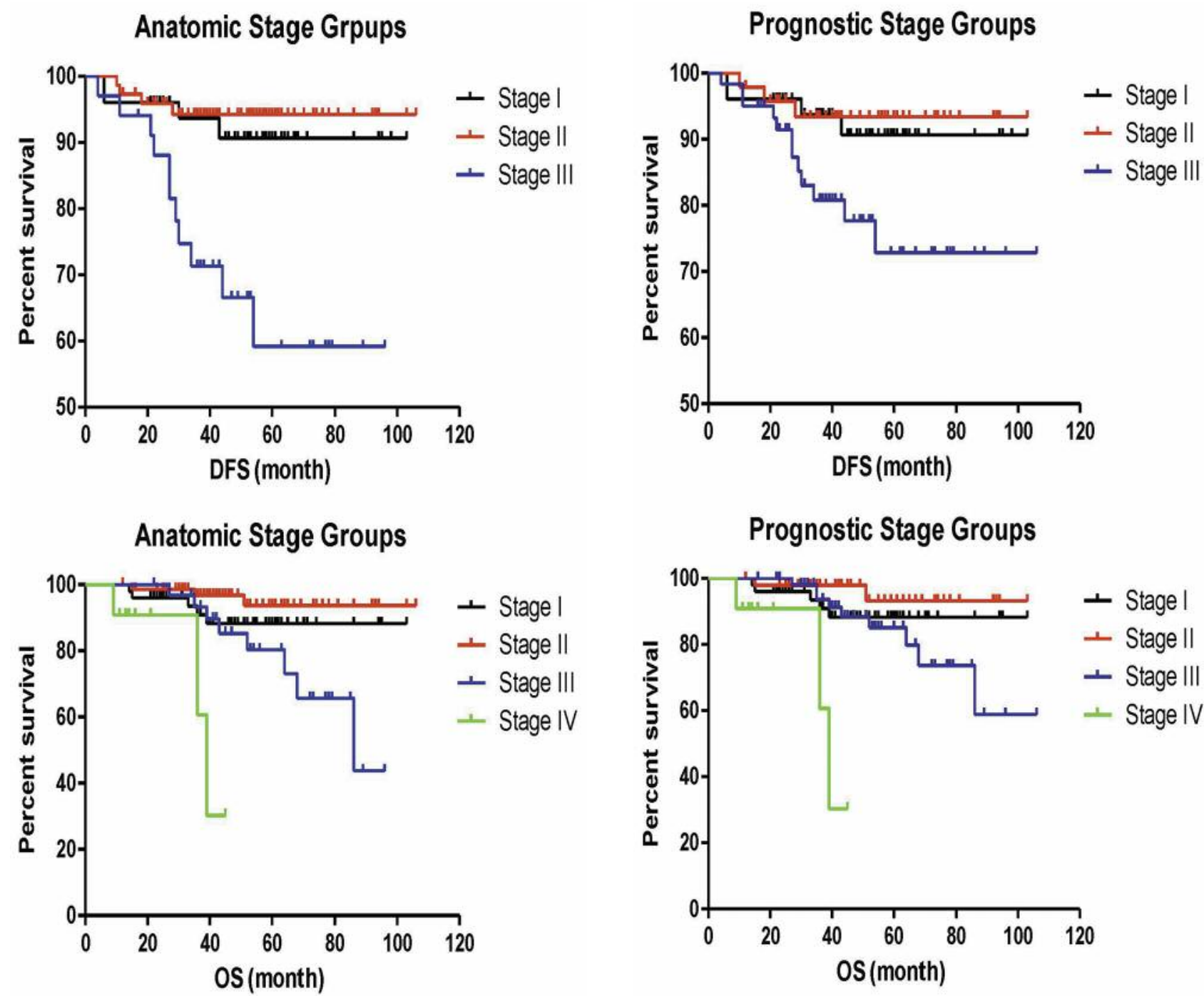

Figure 2.DFS (a) and OS (b) of different anatomic stage groups. There were significant differences in DFS $\left(\chi^{2}=16.752, p<0.001\right)$ and $O S$ $\left(\chi^{2}=25.038, p<0.001\right)$ between anatomic stage groups.

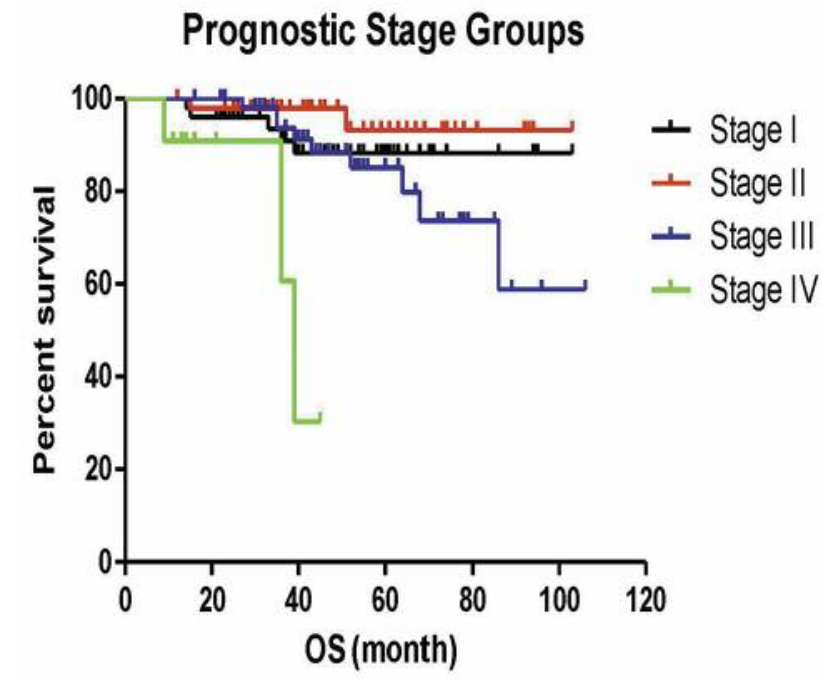

Figure 3. DFS (a) and OS (b) of different prognostic stage groups. There were significant differences in DFS $\left(\chi^{2}=6.577, p=0.037\right)$ and $O S$ $\left(\chi^{2}=21.762, p<0.001\right)$ between prognostic stage groups.

Table II. Numbers, proportions, 5-year DFS and OS of different anatomic and prognostic stage groups

\begin{tabular}{|c|c|c|c|c|c|c|c|}
\hline Anatomic Stage Group & $\mathrm{N}(\%)$ & 5-year DFS (\%) & 5 -year OS (\%) & Prognostic Stage Group & $\mathrm{N}(\%)$ & 5-year DFS (\%) & 5-year OS (\%) \\
\hline Stage I & $51(30.0)$ & 90.7 & 88.3 & Stage I & $51(30.0)$ & 90.7 & 88.3 \\
\hline IA & $49(28.8)$ & & & IA & $1(0.6)$ & & \\
\hline IB & $2(1.2)$ & & & IB & $50(29.4)$ & & \\
\hline Stage II & $74(43.5)$ & 94.2 & 93.7 & Stage II & $48(28.2)$ & 93.4 & 93.2 \\
\hline IIA & $48(28.2)$ & & & IIA & $19(11.2)$ & & \\
\hline IIB & $26(15.3)$ & & & IIB & $29(17.1)$ & & \\
\hline Stage III & $34(20)$ & 59.2 & 80.3 & Stage III & $60(35.3)$ & 72.8 & 85.1 \\
\hline IIIA & $20(11.8)$ & & & IIIA & $35(20.6)$ & & \\
\hline IIIB & $2(1.2)$ & & & IIIB & $12(7.1)$ & & \\
\hline IIIC & $12(7.1)$ & & & IIIC & $13(7.6)$ & & \\
\hline Stage IV & $11(6.5)$ & & 30.3 & Stage IV & $11(6.5)$ & & 30.3 \\
\hline
\end{tabular}




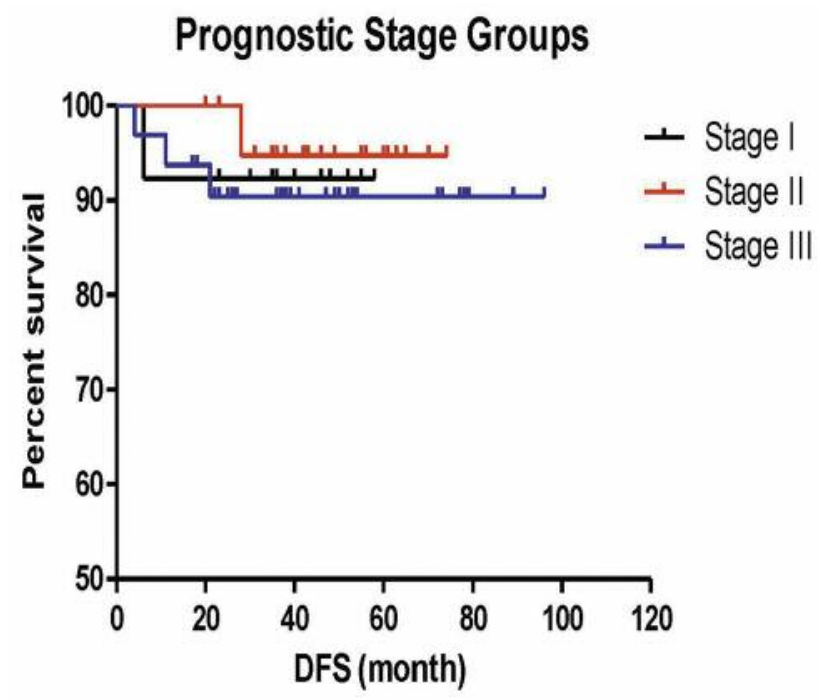

Table III. Differences of stages when changed from anatomic to prognostic stage groups.

\begin{tabular}{|c|c|c|c|c|c|c|c|}
\hline \multirow{2}{*}{\multicolumn{2}{|c|}{$\begin{array}{l}\text { Anatomic Stage } \\
\text { Groups }\end{array}$}} & \multicolumn{6}{|c|}{ Prognostic Stage Groups } \\
\hline & & \multicolumn{2}{|c|}{ Unchanged } & \multicolumn{2}{|c|}{ Upstaged } & \multicolumn{2}{|c|}{ Downstaged } \\
\hline Stage & $\mathrm{N}$ & Stage & $\mathrm{N}$ & Stage & $\mathrm{N}$ & Stage & $\mathrm{N}$ \\
\hline IA & 49 & IA & 1 & IB & 48 & & \\
\hline IB & 2 & IB & 2 & & & & \\
\hline IIA & 48 & IIA & 19 & IIB & 29 & & \\
\hline IIB & 26 & & & IIIA & 26 & & \\
\hline IIIA & 20 & IIIA & 9 & IIIB & 11 & & \\
\hline IIIB & 2 & & & IIIC & 2 & & \\
\hline IIIC & 12 & IIIC & 11 & & & IIIB & 1 \\
\hline IV & 11 & IV & 11 & & & & \\
\hline
\end{tabular}

Table IV. Results of multivariate analysis of predictor of OS using proportional hazard Cox models

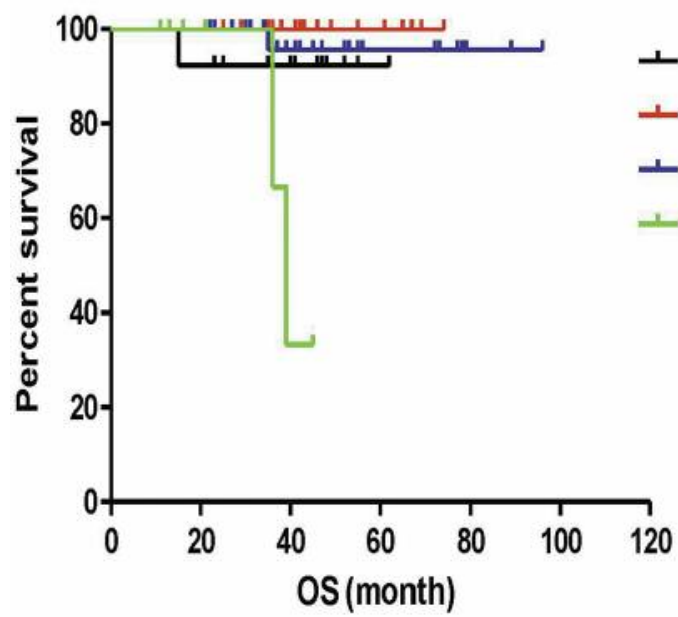

\begin{tabular}{lcccc}
\hline Characteristic & \multicolumn{3}{c}{ OS } \\
\cline { 2 - 4 } & HR & \multicolumn{2}{c}{$95 \%$ CI } & -Value \\
\cline { 2 - 4 } & & Lower & Upper \\
\cline { 3 - 4 } & & & & 0.004 \\
\hline Anatomic stage & Ref & & & \\
I & 0.480 & 0.114 & 2.024 & 0.317 \\
II & 2.532 & 0.820 & 7.814 & 0.106 \\
III & 7.584 & 1.711 & 33.611 & 0.008 \\
IV & & & & 0.018 \\
Prognostic stage & Ref & & & \\
I & 0.504 & 0.096 & 2.650 & 0.419 \\
II & 1.604 & 0.536 & 4.800 & 0.398 \\
III & 7.760 & 1.747 & 34.466 & 0.007 \\
IV & 1.060 & 1.020 & 1.102 & 0.003 \\
Age & & & &
\end{tabular}

Figure 4. DFS(a) and OS(b) of different prognostic stage groups in patients treated with trastuzumab. There were significant differences in OS $\left(\chi^{2}=15.117, p=0.002\right)$ and no significant difference in DFS $\left(\chi^{2}=0.470, p=0.791\right)$ between prognostic stage groups.

Anatomic Staging Groups in the 8th edition, the Prognostic Staging Groups were more recommended. There was no study reporting the prognostic value of the 8th edition of the AJCC breast cancer staging system in different molecular subtypes.

Results of our study showed that both the anatomic and prognostic staging system could predict prognosis of HER2enriched subtype breast cancer patients. The combination of traditional anatomic information reflecting tumor burden and biological information reflecting intrinsic characteristics of tumor can provide a more rational and diversified basis for physicians to understand the feature of a specific tumor and

Table V. Proportions of application of trastuzumab every year from 2008 to 2014

\begin{tabular}{lcc}
\hline Year & $\begin{array}{c}\text { No. of } \\
\text { patients }\end{array}$ & $\begin{array}{c}\text { Proportion of application } \\
\text { of trastuzumab (\%) }\end{array}$ \\
\hline 2008 & 9 & $1(11.1)$ \\
2009 & 17 & $3(17.6)$ \\
2010 & 19 & $7(36.8)$ \\
2011 & 27 & $7(25.9)$ \\
2012 & 34 & $19(55.9)$ \\
2013 & 30 & $20(66.7)$ \\
2014 & 34 & $18(52.9)$ \\
\hline
\end{tabular}


Table VI. Proportions of application of trastuzumab in different anatomic and prognostic stage groups.

\begin{tabular}{|c|c|c|c|c|c|c|c|c|c|c|}
\hline \multirow[t]{3}{*}{ Stage } & \multicolumn{3}{|c|}{ Anatomic stage groups } & \multirow[b]{3}{*}{$\chi^{2}$} & \multirow[b]{3}{*}{$p$-Value } & \multicolumn{3}{|c|}{ Prognostic stage groups } & \multirow[b]{3}{*}{$\chi^{2}$} & \multirow[b]{3}{*}{$p$-Value } \\
\hline & \multicolumn{2}{|c|}{ Trastuzumab } & \multirow[t]{2}{*}{ Total } & & & \multicolumn{2}{|c|}{ Trastuzumab } & \multirow[t]{2}{*}{ Total } & & \\
\hline & Yes N (\%) & No $(\%)$ & & & & Yes N $(\%)$ & No $N(\%)$ & & & \\
\hline I & $13(25.5)$ & $38(74.5)$ & 51 & 16.509 & 0.001 & $13(25.5)$ & $38(74.5)$ & 51 & 15.589 & 0.001 \\
\hline II & $33(44.6)$ & $41(55.4)$ & 74 & & & $21(43.8)$ & $27(56.3)$ & 48 & & \\
\hline III & $20(58.8)$ & $14(41.2)$ & 34 & & & $32(53.3)$ & $28(46.7)$ & 60 & & \\
\hline IV & $9(81.8)$ & $2(18.2)$ & 11 & & & $9(81.8)$ & $2(18.2)$ & 11 & & \\
\hline
\end{tabular}

make a more personalized treatment decision (8). The AJCC recommended the Prognostic Stage Groups, the Anatomic Stage Groups, which remains the basis of the cancer staging system, should be mainly used in regions with limited resources.

In theory, the precondition of using the Prognostic Stage Groups is that patients with breast cancer are treated with appropriate therapy. Especially for the HER2-enriched subtype breast cancer, the prognosis is influenced to a large extent by the use of trastuzumab. In this retrospective study, patients were diagnosed and treated between 2008 and 2014. Although after August 2011, the implantation of a charity program which supported patients to finish trastuzumab therapy reduced economic strain and raised the percentage of application, there remained a significant portion of the patients that could not afford this rather costly therapy. In our single center, the proportion of application of trastuzumab was higher in high-risk subgroups. This is likely due to the different compliance in different subgroups. Results of our study support the notion that trastuzumab could improve the prognosis of HER2positive patients, similarly to previous studies (9-11). Taken together, the better prognosis of stage II than stage I may be due to the bias caused by the use of trastuzumab. Previous studies have shown that HER2 overexpression is a major risk factor of recurrence in small breast cancer and trastuzumab could improve the prognosis of small HER2positive breast cancer $(12,13)$. Our study emphasized one more time the importance of using trastuzumab in the HER2-enriched subtype breast cancer especially in the early-stage subgroup. As to the patients treated with trastuzumab, the result that there was no significant difference between different prognostic stage groups in DFS may be associated with insufficient number of patients and the low event rate in this group.

In this study, prognostic stage was different from the anatomic stage in $68.8 \%$ of patients. All patients which were anatomic stage I and III remained prognostic stage I and III. Among 49 patients in anatomic stage IA, 48 were upstaged to prognostic stage IB. 26 of 74 patients $(35.1 \%)$ in anatomic stage II were upstaged to prognostic stage III. Previous studies have shown that the prognosis of the HER2-enriched subtype was worse than that of luminal subtypes (14-16). These changes proved the tendency of upstaging in prognostic stage compared with anatomic stage, which is valuable to making a more rational treatment decision in HER2-enriched subtype.

In conclusion, our study, the first in evaluating a HER-2 enriched cohort of breast cancer using the AJCC 8th edition staging system, suggests that in this molecular subtype, upstaging is related to histological grade. The majority of HER2-enriched subtype patients are high-grade, consistent with the high proportion of upstaging. It is reasonable to insist on treating HER2-enriched subtype patients with the combination of trastuzumab and cytotoxic drugs. Our result is a clear reminder of the necessity of precise determination of histological grade.

\section{Conflicts of Interest}

The Authors issued no conflicts of interest.

\section{Acknowledgements}

The Authors would like to thank the research team and colleagues participated in this study.

This study is supported by research grants from the Beijing Municipal Commission of Health and Family Planning (No. 20091100) and from the Beijing Municipal Science and Technology Commission (No. D090507043409010 and Z131107002213007) and from Precision Medicine Special Project of National Key Research and Development Program (2016YFC0901302).

\section{References}

1 Amin MB, Edge S, Greene FL and Byrd DR: AJCC Cancer Staging Manual. 8th ed, New York, Springer, 2016.

2 Hammond ME, Hayes DF, Dowsett M, Allred DC, Hagerty KL, Badve S, Fitzgibbons PL, Francis G, Goldstein NS, Hayes M, Hicks DG, Lester S, Love R, Mangu PB, McShane L, Miller K, 
Osborne CK, Paik S, Perlmutter J, Rhodes A, Sasano H, Schwartz JN, Sweep FC, Taube S, Torlakovic EE, Valenstein P, Viale G, Visscher D, Wheeler T, Williams RB, Wittliff JL and Wolff AC: American Society of Clinical Oncology/College Of American Pathologists guideline recommendations for immunohistochemical testing of estrogen and progesterone receptors in breast cancer. J Clin Oncol 28: 2784-2795, 2010.

3 Wolff AC, Hammond ME, Hicks DG, Dowsett M, McShane LM, Allison KH, Allred DC, Bartlett JM, Bilous M, Fitzgibbons P, Hanna W, Jenkins RB, Mangu PB, Paik S, Perez EA, Press MF, Spears PA, Vance GH, Viale G and Hayes DF: Recommendations for human epidermal growth factor receptor 2 testing in breast cancer: American Society of Clinical Oncology/College of American Pathologists clinical practice guideline update. J Clin Oncol 31: 3997-4013, 2013.

4 Elston CW and Ellis IO: Pathological prognostic factors in breast cancer. I. The value of histological grade in breast cancer: experience from a large study with long-term follow-up. Histopathology 19: 403-410, 1991.

5 Goldhirsch A, Wood WC, Coates AS, Gelber RD, Thurlimann B and Senn HJ: Strategies for subtypes - dealing with the diversity of breast cancer: highlights of the St. Gallen International Expert Consensus on the Primary Therapy of Early Breast Cancer 2011. Ann Oncol 22: 1736-1747, 2011.

6 Singletary SE and Connolly JL: Breast cancer staging: working with the sixth edition of the AJCC Cancer Staging Manual. CA Cancer J Clin 56: 37-47, 2006.

7 Giuliano AE, Connolly JL, Edge SB, Mittendorf EA, Rugo HS, Solin LJ, Weaver DL, Winchester DJ and Hortobagyi GN: Breast Cancer-Major changes in the American Joint Committee on Cancer eighth edition cancer staging manual. CA Cancer J Clin, 2017. doi: 10.3322/caac.21393. [Epub ahead of print]

8 Amin MB, Greene FL, Edge SB, Compton CC, Gershenwald JE, Brookland RK, Meyer L, Gress DM, Byrd DR and Winchester DP: The Eighth Edition AJCC Cancer Staging Manual: Continuing to build a bridge from a population-based to a more "personalized" approach to cancer staging. CA Cancer J Clin 67: 93-99, 2017.

9 Cameron D, Piccart-Gebhart MJ, Gelber RD, Procter M, Goldhirsch A, de Azambuja E, Castro GJ, Untch M, Smith I, Gianni L, Baselga J, Al-Sakaff N, Lauer S, McFadden E, Leyland-Jones B, Bell R, Dowsett M and Jackisch C: 11 years' follow-up of trastuzumab after adjuvant chemotherapy in HER2positive early breast cancer: final analysis of the HERceptin Adjuvant (HERA) trial. Lancet 389: 1195-1205, 2017.

10 Jones SE, Collea R, Paul D, Sedlacek S, Favret AM, Gore IJ, Lindquist DL, Holmes FA, Allison MA, Brooks BD, Portillo RM, Vukelja SJ, Steinberg MS, Stokoe C, Crockett MW, Wang Y, Asmar L, Robert NJ and O'Shaughnessy J: Adjuvant docetaxel and cyclophosphamide plus trastuzumab in patients with HER2-amplified early stage breast cancer: a single-group, open-label, phase 2 study. Lancet Oncol 14: 1121-1128, 2013.
11 Tolaney SM, Barry WT, Dang CT, Yardley DA, Moy B, Marcom PK, Albain KS, Rugo HS, Eliis M, Chir B, Shapira I, Wolff AC, Carey LA, Overmoyer BA, Partridge AH, Guo H, Hudis CA, Krop IE, Burstein HJ and Winer EP: Adjuvant paclitaxel and trastuzumab for node-negative, HER2-positive breast cancer. $\mathrm{N}$ Engl J Med 372: 134-141, 2015.

12 Rouanet P, Roger P, Rousseau E, Thibault S, Romieu G, Mathieu A, Cretin J, Barneon G, Granier M, Maran-Gonzalez A, Daures JP, Boissiere F and Bibeau F: HER2 overexpression a major risk factor for recurrence in pT1a-bN0M0 breast cancer: results from a French regional cohort. Cancer Med 3: 134-142, 2014.

13 O'Sullivan CC, Bradbury I, Campbell C, Spielmann M, Perez EA, Joensuu H, Costantino JP, Delaloge S, Rastogi P, Zardavas D, Ballman KV, Holmes E, de Azambuja E, Piccart-Gebhart M, Zujewski JA and Gelber RD: Efficacy of adjuvant trastuzumab for patients with human epidermal growth factor receptor 2-positive early breast cancer and tumors $\leq 2 \mathrm{~cm}$ : a meta-analysis of the randomized trastuzumab trials. J Clin Oncol 33: 2600-2608, 2015.

14 Hennigs A, Riedel F, Gondos A, Sinn P, Schirmacher P, Marme F, Jager D, Kauczor HU, Stieber A, Lindel K, Debus J, Golatta M, Schutz F, Sohn C, Heil J and Schneeweiss A: Prognosis of breast cancer molecular subtypes in routine clinical care: A large prospective cohort study. BMC Cancer 16: 734, 2016.

15 Brouckaert O, Laenen A, Vanderhaegen J, Wildiers H, Leunen K, Amant F, Berteloot P, Smeets A, Paridaens R, Christiaens MR, Floris G, Moerman P, Van Limbergen E, Peeters S, Weltens C, Vergote I and Neven P: Applying the 2011 St Gallen panel of prognostic markers on a large single hospital cohort of consecutively treated primary operable breast cancers. Ann Oncol 23: 2578-2584, 2012.

16 Minicozzi P, Bella F, Toss A, Giacomin A, Fusco M, Zarcone M, Tumino R, Falcini F, Cesaraccio R, Candela G, La Rosa F, Federico $M$ and Sant M: Relative and disease-free survival for breast cancer in relation to subtype: a population-based study. J Cancer Res Clin Oncol 139: 1569-1577, 2013.
Received May 19, 2017

Revised June 6, 2017

Accepted June 7, 2017 